\section{Commentary: Is papillary muscle approximation the key to durable functional mitral regurgitation repair? Only time will tell}

\author{
Robert B. Hawkins, MD, MSc, and \\ J. Hunter Mehaffey, MD, MSc
}

Functional mitral regurgitation (FMR) is at a critical crossroads in cardiac surgery. The Cardiothoracic Surgery Network trial demonstrated equivalent mortality with concomitant repair and replacement at 2 years. ${ }^{1}$ An important finding buried in these data was that patients with durable repair had excellent reverse remodeling and improved quality of life, and a result likely superior to replacement. ${ }^{1}$ But with $58 \%$ of repair patients having at least moderate MR at 2 years, the end result has been a greater number of replacements performed. This is a concerning trend for some cardiologists, and a reason the 3-year results of Cardiovascular Outcomes Assessment of the MitraClip Percutaneous Therapy for Heart Failure Patients with Functional Mitral Regurgitation (COAPT) were so well received. ${ }^{2}$ If cardiologists can repair FMR, why can't surgeons?

Zhan-Moodie and colleagues ${ }^{3}$ present their most recent work evaluating papillary muscle approximation (PMA), a potential adjunct with the purpose of improving FMR repair durability. The authors present their ex vivo modeling of FMR that shows reduced tethering and reduced cordal forces with the end result of improved coaptation. The addition of annuloplasty ring alone reduced the regurgitatant fraction from a mean of $16 \%$ down to between $5 \%$ and $6 \%$. Although the addition of the papillary approximation significant reduced regurgitation further, the decrease was small with an end mean result of $3.7 \%$ to $3.8 \%$ regurgitant

\footnotetext{
From the Division of Thoracic and Cardiovascular Surgery, University of Virginia, Charlottesville, va.

Disclosures: The authors reported no conflicts of interest.

The Journal policy requires editors and reviewers to disclose conflicts of interest and to decline handling or reviewing manuscripts for which they may have a conflict of interest. The editors and reviewers of this article have no conflicts of interest.

Received for publication May 25, 2021; revisions received May 25, 2021; accepted for publication May 26, 2021; available ahead of print June 22, 2021.

Address for reprints: Robert B. Hawkins, MD, MSc, Division of Thoracic and Cardiovascular Surgery, University of Virginia, PO Box 800679, Charlottesville, VA 22908 (E-mail: rbh6x@virginia.edu).

JTCVS Open 2021;7:107-8

2666-2736

Copyright (c) 2021 The Author(s). Published by Elsevier Inc. on behalf of The American Association for Thoracic Surgery. This is an open access article under the CC BY-NC-ND license (http://creativecommons.org/licenses/by-nc-nd/4.0/).

https://doi.org/10.1016/j.xjon.2021.05.014
}

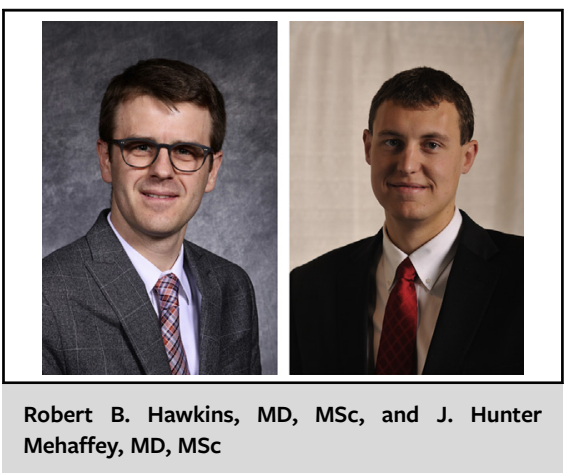

CENTRAL MESSAGE

PMA reduces cordal forces, improves leaflet mobility, and reduces regurgitation in an ex vivo model of FMR. Further research is needed to evaluate PMA durability.

fraction. This contrasts with the marginal cordal forces that were unchanged by annuloplasty alone, but reduced with PMA. This was particularly evident for true-sized annuloplasty rings, which may represent an opportunity to save repairs where the annuloplasty ring was not downsized sufficiently. The end result of these 2 factors was improved bileaflet mobility as evidenced by the excursion angles.

In vivo animal modeling of secondary MR is difficult, with recent publications further helping to clarify tethering in acute ischemic regurgitation and a tachycardia induced functional regurgitation model. ${ }^{4}$ In particular controversy exists over consistency of, and degree to which the anterolateral and posteromedial papillary muscles become displaced. As we all recognize, differing mechanisms of regurgitation result from differing ischemic patterns and no single model will be sufficient. ${ }^{5}$ In this case, the authors were able to assess multiple patterns of papillary displacement in their ex vivo model. Although this is a benefit in early exploratory evaluations, an in vivo model will be a necessary bridge before human application.

Although PMA is not a common repair adjunct, this research helps to highlight the variable mechanisms and mechanics of FMR across patients. A durable repair of FMR need to be the long-term goal for cardiac surgeons if we are to compete with transcatheter technologies. Identifying the leaflet and subvalvar features that predict a highly durable repair will be key selection of patients for repair of FMR. Papillary approximation may help expand that 
cohort appropriate for repair and improve durability for those with papillary displacement.

\section{References}

1. Goldstein D, Moskowitz AJ, Gelijns AC, Ailawadi G, Parides MK, Perrault LP, et al. Two-year outcomes of surgical treatment of severe ischemic mitral regurgitation. N Engl J Med. 2016;374:344-53.

2. Mack MJ, Lindenfeld J, Abraham WT, Kar S, Lim DS, Mishell JM, et al. 3-Year outcomes of transcatheter mitral valve repair in patients with heart failure. J Am Coll Cardiol. 2021;77:1029-40.
3. Zhan-Moodie S, Xu D, Suresh KS, He Q, Onohara D, Kalra K, et al. Papillary muscle approximation reduces systolic tethering forces and improves mitral valve closure in the repair of functional mitral regurgitation. J Thorac Cardiovasc Surg Open. 2021;7:91-104.

4. Bothe W, Timek TA, Tibayan FA, Walther M, Daughters GT, Ingels NB Jr, et al. Characterization of 3-dimensional papillary muscle displacement in in vivo ovine models of ischemic/functional mitral regurgitation. J Thorac Cardiovasc Surg. 2019;157:1444-9.

5. Topilsky Y, Vaturi O, Watanabe N, Bichara V, Nkomo VT, Michelena H, et al. Real-time 3-dimensional dynamics of functional mitral regurgitation: a prospective quantitative and mechanistic study. J Am Heart Assoc. 2013;2:e000039. 